\title{
3
}

\section{Coming Home}

You can have no idea, said Peter irrelevantly, how refreshing it is to talk to somebody who has a grasp of method.... You've got to show how the thing was done, and then, if you like, bring in motive to back up your proof. If a thing could only have been done one way, and if only one person could have done it that way, then you've got your criminal, motive or no motive.

-Dorothy Sayers

An anthropologist studying her own culture has more to worry about than just whether the people she is working with understand what anthropology is. In some ways working in your own society is easier-you are familiar with the language, the "national identity" of your subjects, and the general political, economic, and cultural milieu in which they exist. You are less likely to make major mistakes in etiquette, and you already know how to locate food, mail, entertainment, transportation, and restroom facilities. You probably can identify different types of kin relations, have a general sense of what people in different occupations do, and have a basic history of race, class, and gender relations.

Yet any anthropologist who has "come home" to work knows the difficulties. Carol Greenhouse describes the situation well: "Americans at work in the U.S. must become anthropologists all over again" (I 985:26I). An important part of this reeducation is learning to see the everyday and the mundane as data that help tell the ethnographic story. Road signs, graffiti, newspaper ads, the movie playing at the local theater, the merchandise in the local market or mall, clothing and hairstyles, the appearance of yards and houses, the food in restaurants-all things that an anthropologist working in another culture would never think of ignoring-need to be considered as data here too. 
The traditional participant-observer role that an anthropologist can play in a foreign land also gets subverted at home. In this role anthropologists actively participate in the community they are studying while also trying to maintain a "scientific" or "objective" distance. Objectivity is difficult to maintain, however, for communities have every reason to assume that you, as another American and an incipient community member, ought to fit into preexisting roles or categories and should not be maintaining this illogical distance from your neighbors, asking them all sorts of questions.

During my work in Seneca County and at the peace camp, the roles assigned to me by different groups provided a record of how people classify themselves and outsiders. It also indicates that each group attempted to appropriate me, as they would try to recruit any potential new community member, to their own camp. Accepting the anthropologist as a community member is in some ways designed to neutralize her research or at least to confuse her loyalties. For example, one of my interviewees introduced me to a group of middle- and upper-middle-class women who met weekly to play Trivial Pursuit. They accepted me as a player, but I was never able to direct their attention away from the game and toward addressing my own pursuit of peace camp gossip. A group of working women accepted me as a member of their softball team, but only one postgame session in everyone's favorite softball bar led to a fruitful, if uneasy, discussion of the peace camp.

Many of the local veterans and members of the Veterans of Foreign Wars post considered me a friendly ear, willing to listen to their side of the story and enabling them to relive and relieve the tensions of the summer of I983. More than one person commented that talking to me was like a session with a psychiatrist! Despite a sign in the VFW bar which said, "What you see here, What you hear here, When you leave, Leave it here," I was encouraged to take the stories they told away with me. And many of the community women that I talked to on a more formal, less involved basis used the opportunity to air their concerns not only about the peace camp but also about local conditions for women.

At the encampment I was required to play different roles at different times. In 1983 I was quite simply another participant, albeit one carrying a video camera. Upon my arrival in Seneca Falls with my female video partner to visit the historical sites before we went to the camp, an encampment women came up to us and said, "I would recognize two dykes anywhere!" We didn't want to counter her incorrect assumption, and we laughed to ourselves that we were so readily identified as members of the 


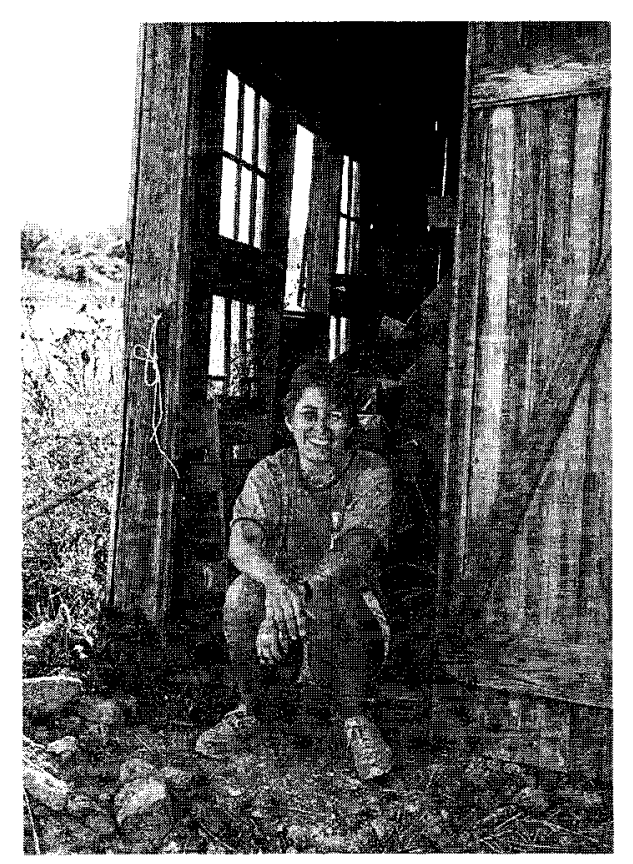

Louise Krasniewicz at the encampment, 1983 . Photographer unknown

encampment constituency. I was to learn through my research in the next several years that appearing to be a lesbian because of clothes, manner, or interest in women's issues was a key factor for acceptance in the post- I 983 encampment community. The "discovery" that I was not a lesbian (usually because someone would directly question me) while I was doing this later research often led to hostility and suspicion at the post-I 983 encampment. By contrast, this information usually comforted Seneca County residents, who then more easily assimilated me into their conversations and groups.

Those at the encampment assumed that any woman coming to the peace camp would actively and fully participate in routine and ritual. Although it was easy in I983 to spend more time observing than participating, my observation habits were noticed and commented on in the smaller encampment community of later years. During a particularly emotional regional meeting in 1985 , some women noted that I did not become involved in the antagonistic or emotional discussions that took place "from the heart," and they objected to my aloofness. My refusal to walk on hot coals in a ritual fire walk was not problematic, however, because I had participated in other aspects of the ritual and many other 
women also did not actually do the walk. Some of the encampment organizers believed that my study of their community legitimated their efforts, and they were willing to accept any level of participation or observation. Other women were unwilling to accept anything less than complete immersion in a separatist ideology and goddess-based spiritualism, and some became suspicious that I was spying for the army.

An anthropologist working in the United States thus has not only the traditional problem of juggling participation and observation but also the problem of switching sympathies among the many communities and factions that try to claim her as a logical member of their group. In a foreign place, an anthropologist is a clear and definite outsider, but in her own country, she discovers little comfort in trying to fall back on her professional status as an excuse for distancing herself from the communities she studies.

In the summer of 1986 I returned to Seneca County for four months of field research. I had attended the peace encampment in 1983 not quite as an anthropologist but also not exactly as a participating protestor. I was acquainted with some of the early organizers, who, as plans were being developed for the encampment, encouraged women with access to media equipment to document the activities. I joined in the effort to record the planning, building, and operation of this all-women's peace camp, attending twice in the summer of 1983 for a total of six days.

I have to admit that at first I had doubts about the ability of a group of feminist activists to carry out such an impressive enterprise. I had already seen the political and philosophical differences among women collapse concrete action into a pile of rhetoric many times. I was convinced that the organizers had miscalculated the amount of food, money, portable toilets and neighborly goodwill needed for the encampment's development. I was later to learn that many of the encampment organizers had had extensive experience organizing successful and safe music festivals that attracted thousands of women from throughout the country.

Although I was not "officially" an anthropologist at the time, my documentation work provided me with a chance both to participate and to distance myself from a project in which I did not have much confidence The use of a video camera provides the documenter with the same kind of participant-observer status that the anthropologist employs. It provides a license to observe from both inside and outside at the same time and to participate only as desired, with the "need" to record sometimes providing a good excuse not to be actively involved.

My decision to conduct more extensive research on the events sur- 
rounding the encampment arose at least partly from the nature of the experience. Many, or perhaps even most, women (myself included) were greatly moved by their participation. My initial misgivings were wiped away by a politically and socially stimulating community that offered a view of an alternative world. In $1984 \mathrm{I}$ began attending regional encampment meetings as well as visiting the encampment, talking to some of the early organizers, and consulting the extensive encampment files. My analysis of 1983 was planned to include both accounts recorded at that time (from videotapes, audiotapes, photographs, journals, records, newspapers, etc.) and retrospective narrative accounts obtained from local residents and encampment women.

Not all anthropologists agree that the changes and trends described in the previous chapter are significant or positive for the discipline called anthropology. My own confrontation with this other current voice of anthropology came in the middle of my summer of fieldwork in Seneca County. I was in the offices of Seneca County's weekly newspaper, the Reveille, one day when Howard Van Kirk, the publisher, mentioned that another anthropologist had just walked in to use the copying machine. I was relieved to find out he was a folklorist collecting traditional folk stories until he told me that he had done his own brief study of the events related to the nuclear protests. The problems of that summer were easy to understand, he assured me, and they did not merit a summer of fieldwork or lengthy study. Echoing the exact words used by so many residents, newspaper reporters, and local officials, he told me that the problem in I 983 was that "the women came into a rural, conservative community that was not used to these kinds of activities." The most significant thing to understand, he insisted, was that people's main concern was economic - the local people were economically dependent on the army depot and were afraid of what would happen to people's jobs if it closed. It was plain and simple, he explained; people were motivated by economic factors and all the other so-called issues-witchcraft, lesbianism, nudity, and the American flag-were peripheral and basically insignificant. He didn't see what I could possibly have left to study: he felt he had answered the most important question of why Seneca County reacted so negatively toward the encampment women. From his point of view, my only options were to do an intensive analysis of the local economy or give up the project and go home.

My approach to the situation, I tried to explain to him, was quite different. I was not so much interested in proving why the events of 1983 took place as in describing how they took place and how people organized 
their understanding of these events. Asking why certainly leads to a reassuring closure (Why did the local people dislike the encampment women? Because they were afraid of losing their jobs and having higher taxes), but it is a closure that suppresses the richness of human social action. Such a mechanistic explanation is also too removed from the farreaching effects of these events on the everyday lives of the individuals and the communities involved.

I was sure that my interest in effects rather than causes required me to analyze social action as Clifford Geertz has suggested, using a multidisciplinary approach that considers culture semiotically, as a "web of significance" requiring interpretation (1973:5). Geertz's interest in "connecting action to its sense rather than behavior to its determinants" (1983:34) works with a culture-as-text analogy and with the search for how a text means. This shift to behavior and action as textual discourse seemed to provide the right approach for my study. When applied to the events of 1983 in Seneca County, New York, this approach led to an analysis of the texts produced about the discursive conflicts that took place that summer.

It was to become a major goal of my project to investigate the not-soinnocent purposes for which the people involved in this conflict produced, interpreted, manipulated, and experienced narratives or stories about the summer of 1983 . In uncovering these narratives, I wanted to see how individuals and groups were both in control of and controlled by their stories; I wanted to see how they used narratives to make sense of those activities they supposedly were not used to seeing or experiencing. This search for the how of human behavior through the analysis of textual strategies was more complex than a search for the definitive why, but I thought it would provide a richer story of these events.

I wanted to approach social actions as textual products used in the context of a discourse. These textual actions asked not for definitive explanation but for careful readings; the delineation of their discursive context would show how people made the decisions they did and what constraints affected both collective and individual decisions and actions. I was interested in how people textualize their lives, how they both read and write themselves in and into the world.

The conflicts of that summer produced texts in many forms and about many subjects. By considering a range of these texts (for example, newspaper accounts, conversations, videotapes, letters, symbols, rituals, brochures, signs, clothing and appearance, songs) and analyzing their underlying assumptions, rules of organization, exclusions, and applications, we 
can see how these texts are constructed. The desired result of these productions, which all factions attempted to achieve, was a control of the interpretation and effects of the summer's events.

How did people know, as the other anthropologist claimed they did, how to interpret and categorize the women properly and correctly if, as everyone insisted, the local communities had never been confronted with this type of behavior or these kinds of women before? To me it seemed clear that the answer was in discourse because all social activities necessarily take place within discursive constraints, and the meaningfulness of any action is limited by what the discourse allows as a proper interpretation. I wanted to study Seneca County as an "interpretive community" (Fish I 980) that shared an outlook on actions and events. I did not feel that an economic explanation could cover everything that had occurred in 1983.

I explained all this (not in so many words) to the other anthropologist over coffee and later over lunch with him and his father in a Seneca Falls restaurant called Red's Place, which sported a sign that read, "Men's Hall of Fame," mocking the Women's Hall of Fame across the street. We parted ways after lunch, never to communicate again, and I went on to construct a study that had as its purpose the delineation of discursive, interpretive, and textual strategies in Seneca County in 1983.

The suggestion that the most important discourse informing the events of 1983 was economic did not sit well with me when I first heard it. It seemed too simplistically determinist and tended to denigrate nonmaterial analyses as unimportant and less real. Initially, I completely rejected all economic explanations and kept my investigation focused on the symbolic. But economic factors are not inconsistent with the interpretive approach. Our symbolic constraints are heavily affected by material considerations, just as material conditions and explanations are certainly focused and guided by our interpretations. In addition, economic explanations embrace more than just material conditions; they, too, constitute a type of discourse involving the processes of representation and interpretation. This other anthropologist was not wrong to suggest a look at the material conditions of Seneca County; but it is important not to restrict the concept of economics to the traditional concern with the material aspects of life. Clearly some of the motivation for hostility to the encampment can be found in the economic background of Seneca County.

The encampment generated much opposition and had significant effects throughout the entire region. Nevertheless, the county is a useful bureau- 
cratic, economic, and self-identification unit in New York state. It is used to organize such services as sheriff's departments, health departments, and welfare agencies. State funding for special programs in the arts, education, and farming are often determined on a countywide basis. In addition, local residents often organize their own groups such as church parishes or clubs within rather than across county lines. I use "Seneca County," therefore, as a shorthand designation for all the regional people who found themselves drawn into these conflicts, keeping in mind that not all of them resided in Seneca County proper and that not all the county residents were opposed to the encampment.

Like most rural agricultural and manufacturing counties in the late I 970 s and early I 980 os, Seneca County watched its economic base erode. The nonagricultural unemployment rates from the end of 1982 through the first half of 1983 ranged from 9.6 percent to a high of 13.8 percent. When the Philips television plant was partially closed in I 98 I, 402 local jobs were lost, and the 1983 closing of Comtec Corporation meant another I 20 losses. Other, smaller businesses also closed or relocated.

The I 980 os were generally a difficult time nationwide for small-scale farmers like the ones in Seneca County. National farm policies, trade embargoes, and poor weather conditions drove many family farms out of business, especially in the Midwest, where farms that had been worked for generations by a single family were lost to foreclosure. In Seneca County, according to the Seneca County Cooperative Extension office, the situation was not so desperate. The county led the state in soybean production, corn exports, and hog marketing, and was fourth or fifth in milk production. In addition, by 1987 there were twelve hundred acres of grapes growing at thirty-three vineyards, and eleven wineries were in operation, giving a boost not only to agricultural production but also to tourism.

Farmers in Seneca County traditionally experience only a 2.5 to 3 percent return on their crops. When weather conditions are poor, as they were in 1983 , marginal farmers, including many who want to continue farming, are forced to sell out. But unlike those in the Midwest, most farmers in Seneca County remained financially solvent, according to Cooperative Extension, because they were able to sell their land for a good price. Amish and Mennonite farmers, who had begun emigrating from nearby states in the late I 970 , had been purchasing farms and driving up the prices and value of the land. Thus Seneca County escaped the plunge in land prices that devastated the midwestern states.

Outside of agriculture and industry, the Seneca Army Depot and the state psychiatric hospital at Willard were the largest employers. The $R e$ - 
source Handbook published by the encampment contended that "Many of the civilian jobs require a high level of skill or security clearance and are filled by persons who are brought to the depot from outside the Finger Lakes region. Many of the low skills jobs are filled by family members of military personnel stationed at the depot. The end result of this employment situation is that only a small percentage of all the jobs at the depot are open to local people" (Resource Handbook 1983:5). Nevertheless, the Seneca Army Depot employed approximately eight hundred civilian workers during 1983 , and a national trend toward increased defense spending contributed to the depot's image as a strong and stable employer (even though the number of civilian employees had been steadily decreasing). The depot's public information director stated that the depot puts $\$ 33$ million per year in salaries and contracts (including pay to the military personnel) into the regional communities. Although it is difficult to measure how much of that money actually made its way into the local economy (the salaries to military personnel, who had base housing and shopping, were not necessarily spent locally), certainly some of it contributed to Seneca County's economy. The loss of the depot as a source of steady money would have been a blow to the county.

Yet the Seneca Army Depot, as residents would readily state, was not an unambiguously positive economic asset to the local community. The depot is just one of several federal projects that provide needed jobs and services but also bring in unwelcome "outside" influences and take extensive areas of land off the county tax rolls. Local residents often view the SEAD_along with a state park, a wildlife preserve, a national park celebrating women's history, the psychiatric center, and a federal land-use area (failed farms purchased by the government and set aside for cattle grazing and now for recreation) - as yet another sacrifice to be borne by a county that has given more than its fair share of resources to the state and federal governments ( 12 percent of the land in Seneca County and 33 percent in Romulus and Tyre townships is government owned). Yet even as a mixed blessing the depot was generally seen as a sign of the possible economic survival of Seneca County in difficult times.

It is ironic but not inconsistent with their actions that many regional residents not only didn't lose jobs or money because of the encampment but in fact made money providing goods and services to the thousands of protestors, reporters, and curiosity seekers. Extra civilian guards hired by the depot were drawn from the local population, and local restaurants and hotels fed and housed the extra police called in for the large protests. The $\$$ I 95,000 tab for the extra county security services was reimbursed 
within a year by the federal government after lobbying by area politicians. Representative Frank Horton and Senator Alfonse D'Amato argued that the lengthy protests had put a special burden on a rural county that was unable to bear it. The Department of Justice agreed and offered to reimburse the county for security expenses. According to the county budget director in 1984 , all but about $\$ 84,000$ of the bills of 1983 had already been paid with unanticipated extra sales tax revenue; a good portion of the federal money would therefore be counted as additional revenue for the 1984 budget year (Finger Lakes Times, January I I, 1984). Thus the county actually made a profit on the events of 1983 .

In a market economy, economic activities are seen as more important than "merely" cultural ones and usually as distinct from them. But the "economic" discourse surrounding the events of 1983 should be widened to include issues beyond money, profits, employment, and taxes. The activities of that summer could easily be thought of as what Georges Bataille calls an "unproductive expenditure" (1985:118), which, like pleasure and unreproductive sexual activity, is assumed to be wasteful and antisocial. Alternatively, these activities could be seen as part of a network of social exchange which is absolutely necessary for the definition and continuation of the social world. Economic discourses are always intricately interwoven with seemingly noneconomic ones to create the idea of the "economy" as a "ground where self and society both define and confuse ethical and material values," according to Wallace Martin (I 986: I9). As Marshall Sahlins reminds us, the economic basis of a society is also a "symbolic scheme of practical activity" (1976:37), a way of judging and classifying value, functionality, utility, importance, and meaningfulness. When people talk about the economy, they are using one of commonest measures in our society for indicating changes in status, identity, social standing, and values. In her study of rural poverty in upstate New York, Janet Fitchen (198I) has pointed out that changes in the rural economy are often strongly associated with major shifts in the social context; neither is the determining force, and each informs us about the other.

The protests were a compelling social as well as economic drama about which everyone-depot employees or not-seemed curious. As one man explained:

I went down to watch them because I'd never actually seen a protest in person. . . . I went down there [to the depot main gate] and watched. And I just kept watching and watching. ... yeah, it was weird, I was just transfixed; took my wife out there on the motorcycle, and she got into it 
because she was sort of a rebel anyway, being in college and all. But like $I$ said, it was the first time I ever seen anything like that, and I just stayed there for like hours and hours and hours, just watching. . . . That was quite a learning process for me, trying to figure out what they were doing.

Some local residents used the analogy of "coming out to watch a fire to explain the interest in the encampment protests." At a fire everyone wants to know whose house is burning, who discovered the fire, did the fire department respond quickly, was anyone hurt, how much damage there was-questions that build the fire into a human drama that contemplates the nature of social relations and the condition of human beings in an uncertain world. The encampment protests were something that, like a fire; they provided people with the opportunity to confirm, protect, and expand their definition of themselves as members of a community and a world that was both precarious and stable. A combination of curiosity and a desire to be a part of a community event, the wish not to miss out on shared information and activities, certainly could be compelling.

The people watching the antinuclear protests were not necessarily depot workers or relatives of workers out defending their jobs. One active counterdemonstrator who did work at the depot actually lost his job during that summer, and according to his claims, it was precisely because he was counterprotesting and being interviewed in the newspapers that he was laid off. Another prominent counterdemonstrator worked not at the depot but for the local radio station, and he was nearly fired for his vocal protests and visibility at demonstrations. What attracted depot workers and nonworkers alike was a sense that the community was under attack and needed to be defended on all fronts. The events of 1983 provided people with a ritualistic means of contemplating and witnessing exactly those things that could tear their society apart and then those things needed to put their society right again. Like the man who went out to watch, "trying to figure out what they were doing," people were trying to give meaning to what they saw. That meaning was always a combination of the social, the political, and the economic. 